\title{
Pelayanan Komprehensif Terhadap Seorang Penderita Sindrom Metabolik dan Keluarga: Studi Kasus
}

\author{
Comprehensive care to prevent metabolic syndrome: a \\ case study
}

\author{
Erlina Wijayanij $j$ \\ Public Health Department of YARSI University
}

KATA KUNCI
KEYWORDS

ABSTRAK sindrom metabolik, pelayanan komprehensif

metabolic syndrome, comprehensive care

Seorang lelaki, Tn. A berusia 31 tahun mengalami sindrom metabolik ditandai dengan tanda obesitas sentral, hipertensi, dan hiperglikemi. Tn. A memiliki seorang istri dan 3 orang anak yang masih balita. Status gizi istri dan anak masih dalam batas normal (berdasarkan IMT untuk istri dan BB/U untuk anak). Akan tetapi pola makan keluarga sering memilih makanan berlemak. Aktivitas fisik istri tergolong kurang aktif. Selain itu, pola asuh keluarga lebih menyukai anak balita yang gemuk. Peran keluarga sebelum pembinaan memiliki nilai coping score 2. Kemudian dilakukan pembinaan dengan prinsip pencegahan komprehensif pada pasien dan keluarganya. Pada Tn. A dilakukan pencegahan tersier dengan terapi dan perbaikan gaya hidup. Sedangkan pada keluarganya dilakukan pencegahan primer agar berpola hidup sehat (aktivitas fisik, mengurangi konsumsi lemak dan karbohidrat) dan memperbaiki persepsi mengenai pola asuh anak. Pencegahan sekunder berupa penilaian status gizi, pemeriksaan tanda vital dan pemeriksaan gula darah serta profil lipid. Metode pembinaan yang digunakan berupa family conference, konseling dan pendampingan. Pasca pembinaan, coping score meningkat dari skor 2 menjadi lebih dari 4. Kondisi pasien membaik dan keluarga mulai memperbaiki pola hidupnya. Artikel ini juga membahas mengenai natural history of disease dan level of prevention pada sindrom metabolik.

Mr. A 31 years old with metabolic syndrome characterized by central obesity, hypertension, and hyperglycemia. Mr. A has a wife and 3 toddlers. Nutritional status of wife and child was still normal (based on $B M I$ for wife and BB / U for child). However, the family diet often choose fatty foods. Physical activity of the wife was less active. In addition, the pattern of child care prefered toddlers who were overweight. The role of family before coaching reached 2 point in coping score. We coach the comprehensive prevention for patients and his families. Mr. A was given tertiary prevention by therapy and lifestyle improvement. While the 
family were carried out by primary prevention in order to improve healthy lifestyle (physical activity, reduce consumption of fat and carbohydrates) and to fix child care perception. Secondary prevention given by medical check up. Coaching methods that we used such as family conference, counseling and mentoring. Post coaching, coping score increased to higher than 4. Mr. A condition was better and the family's lifestyle improved. This article also discussed the natural history of disease and level of prevention in the metabolic syndrome.

\section{PENDAHULUAN}

Sindroma Metabolik (SM) merupakan kelainan metabolik dengan komponen utama obesitas, resistensi insulin, dislipidemia, dan hipertensi. Sindrom metabolik merupakan kumpulan dari faktor-faktor risiko terjadinya penyakit kardiovaskular. Data dari Himpunan Studi Obesitas Indonesia (HISOBI) menunjukkan prevalensi SM sebesar 13,13\% (Rini S 2015). Untuk mengurangi insiden ataupun memperbaiki outcome, diperlukan pencegahan komprehensif. Pencegahan komprehensif meliputi five level of prevention sesuai dengan riwayat alamiah perjalanan penyakit individu.

\section{ILUSTRASI KASUS}

Seorang pasien laki-laki 31 tahun datang dengan keluhan nyeri kepala sejak 2 hari. Didapatkan tanda hipertensi (180/110mmHg), obesitas sentral (lingkar pinggang 102cm), dan hiperglikemi (gula darah puasa: $138 \mathrm{mg} / \mathrm{dl}$ ). Faktor risiko antara lain kebiasaan makan pasien dengan jumlah yang banyak, faktor genetik dari ibu pasien yang menderita DM dan hipertensi, sering begadang dan kurang aktivitas fisik. Kemudian dilakukan assesmen pada keluarga pasien yaitu istri dan ketiga anak pasien yang masih balita. Istri pasien masih memiliki status gizi normal demikian juga anak pasien masih berstatus gizi cukup. Akan tetapi pola makan keluarga cenderung sering mengkonsumsi lemak. Istri pasien juga tergolong kurang dalam aktivitas fisik. Selain itu pola asuh keluarga yang senang bila anaknya terlihat gemuk. Saat dilakukan penilaian, disimpulkan bahwa coping score keluarga pada skor 2 (mau melakukan tapi tidak mampu, tak ada sumber (hanya keinginan) dalam menyelesaikan masalah).

\section{MANAJEMEN DAN HASILNYA}

Intervensi pencegahan yang dilakukan pada Tn. A dengan pencegahan tersier yaitu memberikan analgesik dan antihipertensi serta perbaikan gaya hidup. Intervensi pada istri dan anak dengan pencegahan primer dan sekunder. Pencegahan primer dengan edukasi kesehatan untuk perbaiki gaya hidup dan pola asuh anak. Pencegahan sekunder dilakukan untuk mendeteksi dini adanya sindrom metabolik pada keluarga pasien dengan medical check up.

Correspondence:

Erlina Wijayanti, IKM FK YARSI, Letjen Suprapto, Jakarta Pusat, Indonesia, Tel. 021-4206674

Email: erlina.wijayanti@yarsi.ac.id 
Tabel 1. Kegiatan Pembinaan Keluarga untuk mencegah sindrom metabolik pada Tn. A dan keluarga

masih tergantung pada upaya provider) dan nilai 5 (dapat dilakukan sepenuhnya oleh keluarga). Hal ini berdampak pada membaiknya kondisi Tn. A. Sebulan kemudian, dilakukan Kegiatan Pembinaan Coping score Coping score

Melakukan family conference mengenai kondisi Tn A yang menderita sindrom metabolik

Melakukan

pemberian informasi terhadap keluarga Tn A mengenai pencegahan sindrom metabolik

(pencegahan primer, sekunder dan tersier) Konseling menentukan diet makan yang sehat 1900 Kal tiap hari, mengurangi

konsumsi lemak jenuh, memilih karbohidrat

kompleks

Konseling menurunkan berat badan bagi Tn A (target BB turun menjadi $65 \mathrm{~kg}$ dalam waktu 6 bulan)

Konseling aktivitas fisik (minimal 30 menit beraktivitas sedang setiap hari untuk Tn. A dan istri serta minimal 1 jam beraktivitas sedang untuk anak-anak Tn.

A)

Konseling mengenai pola asuh anak terutama mengenai gizi anak

Dari tabel di atas, tampak bahwa coping score awal sebelum pembinaan, keluarga Tn. A pada nilai 2 (mau melakukan tapi tidak mampu, tak ada sumber daya) menjadi nilai 4 (mau melakukan namun tak sepenuhnya, $2 \quad 4$ - pemeriksaan fisik pada Tn. A: tekanan darah 140/90mmHg, berat badan turun menjadi $72 \mathrm{~kg}$, kolesterol $165 \mathrm{mg} / \mathrm{dl}$ dan glukosa darah puasa $118 \mathrm{mg} / \mathrm{dl}$ serta lingkar pinggang $98 \mathrm{~cm}$. selain itu, Tn. A dan keluarga sudah memperbanyak aktivitas fisik, mengurangi makanan berlemak dan keluarga memahami mengenai pola asuh gizi untuk anak.

\section{PEMBAHASAN}

Salah satu prinsip pelayanan dokter keluarga adalah pelayanan medis strata pertama untuk semua orang yang bersifat paripurna (comprehensive). Pencegahan yang dilakukan dapat dibagi menjadi 3 tahap yaitu pencegahan primer, sekunder dan tersier. Pencegahan primer adalah usaha untuk memodifikasi faktor risiko atau mencegah berkembangnya faktor risiko sebelum dimulainya proses patologis (proses pre-patogenesis). Pada fase pre-patogenesis, seorang individu dapat berada pada fase rentan/susceptibility. Pencegahan primer terdiri dari promosi kesehatan dan perlindungan spesifik (Kleinbaum DG, Kupper LL and Morgenstern H 1982).

Pencegahan sekunder dilakukan pada fase presimtomatik, yaitu saat penyakit belum menimbulkan gejala. Pencegahan sekunder terdiri dari deteksi dini dan pengobatan dini. Sedangkan pencegahan tersier adalah pencegahan yang dilakukan pada saat penyakit sudah menimbulkan gejala. Tujuan dari pencegahan tersier untuk mencegah perkembangan penyakit ke arah yang lebih buruk (Kleinbaum, D. 
G., Kupper, L. L. and Morgenstern, H., 1982).

Dalam menentukan pencegahan yang akan dilakukan, seorang dokter harus memperhatikan riwayat perjalanan penyakit pasien. Menurut ATP III, sindrom metabolik merupakan kumpulan gejala yang ditandai dengan 3 dari 5 gejala/tanda berikut (Daskalopoulou SS, Mikhailidis DP, \& Elisaf M 2004). Obesitas sentral (Lingkar pinggang $>40$ inci untuk laki-laki dan $>35$ inci untuk wanita), kadar trigliserid darah $>150 \mathrm{mg} / \mathrm{dl}$, kadar HDL $<40 \mathrm{mg} /$ dl untuk laki-laki dan $<50 \mathrm{mg} /$ dl untuk wanita, tekanan darah sistolik $>130 \mathrm{mmHg}$ dan atau diastolik $>85 \mathrm{mmHg}$, kadar gula darah puasa $>110 \mathrm{mg} / \mathrm{dl}$. Seorang individu dikatakan rentan mengalami sindrom metabolik apabila memiliki faktor risiko seperti gaya hidup (makan berlebih (terutama karbohidrat dan lemak), minum alkohol, merokok, kurang beraktivitas fisik), memiliki faktor genetik, kondisi sosial ekonomi dan stress (Kaur J, 2014). Apabila seorang masih dalam fase rentan dan belum mengalami proses patogenesis, maka dapat dilakukan pencegahan primer berupa health promotion dan specific protection (Kleinbaum, D. G., Kupper, L. L. and Morgenstern, H., 1982).

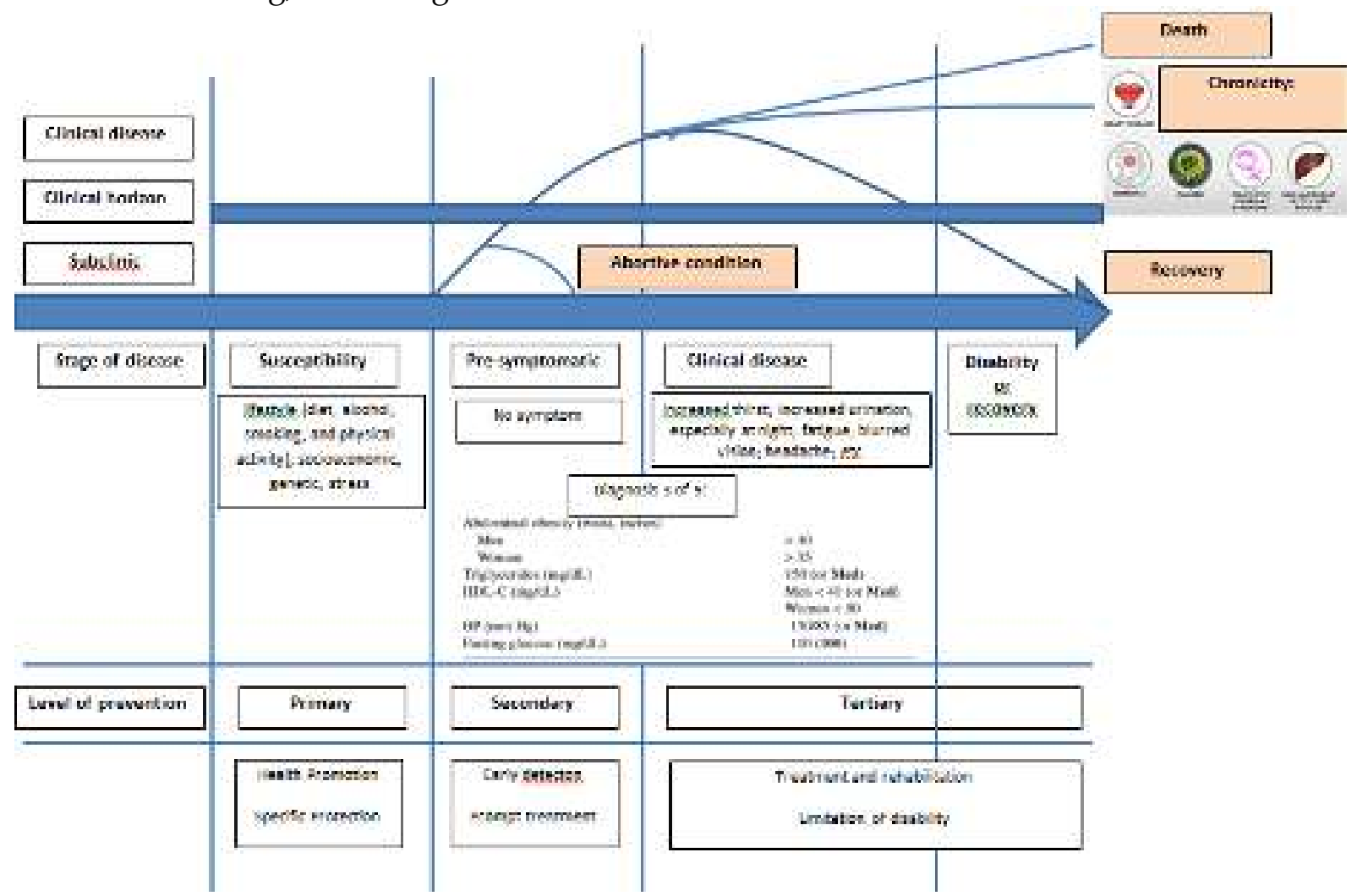

Gambar 1. Natural History of Disease pada sindrom metabolik

Sumber: Daskalopoulou, S. S., Mikhailidis, D. P., \& Elisaf, M, 2004; Kleinbaum, D. G., Kupper, L. L. and Morgenstern, H., 1982

Perbaikan gaya hidup yang dianjurkan adalah diet rendah lemak jenuh, memperbanyak konsumsi buah, gandum, aktivitas fisik teratur (>30 menit per hari) dan menghindari sedentary life (Cornier MA, Dabelea D, Hernandes TL, et al., 2008). Untuk mengetahui fase presimtomatik 
sindrom metabolik, dapat dilakukan deteksi dini dengan pemeriksaan lingkar pinggang, kadar trigliserid, kadar HDL, tekanan darah dan kadar gula puasa walaupun pasien belum mengalami gejala (Kaur J, 2014). Apabila ditemukan tanda ke arah sindrom metabolik, maka dapat dilakukan pencegahan sekunder lain berupa pengobatan dini (Grundy SM, Hansen B, Smith SC Jr, et al., 2004). Apabila pasien sudah mengeluhkan gejala, maka perjalanan penyakit sudah dalam fase patogenesis lanjut/simtomatik dan perlu dilakukan pencegahan tersier berupa disability limitation dan rehabilitation (Kleinbaum DG, Kupper LL and Morgenstern H 1982).

Pada kasus di atas, pasien berada pada fase simtomatik sindrom metabolik. Pasien mengeluhkan sakit kepala, lalu dari pemeriksaan fisik didapatkan tanda hipertensi (180/110 $\mathrm{mmHg}$ ) dan obesitas sentral (lingkar pinggang $102 \mathrm{~cm})$. Dari pemeriksaan laboratorium terdapat hiperglikemi (gula darah puasa: 138mg/dl). Pada pasien ini dilakukan pencegahan tersier berupa pemberian obat antihipertensi dan pembinaan untuk memperbaiki gaya hidup serta menganjurkan pemeriksaan EKG, foto rontgen dan fungsi ginjal. Tujuan dari pencegahan ini agar penyakit tidak berlanjut dan dapat memperbaiki outcome pasien (yaitu pasien sembuh). Pada istri dan anak Tn. A, masih berada dalam fase rentan sehingga perlu dilakukan pencegahan primer dan sekunder.

\section{SIMPULAN}

Angka kejadian sindrom metabolik di Indonesia cukup tinggi. Untuk dapat mengatasi masalah sindrom ini perlu diterapkan pelayanan komprehensif yaitu melakukan pencegahan primer, sekunder dan tersier.

\section{KEPUSTAKAAN}

Cornier MA, Dabelea D, Hernandez TL et al., The metabolic syndrome. Endocr Rev. 2008; Pubmed; 29:777-822. Diakses pada 18 September 2017 dari https://www.ncbi.nlm.nih.gov/pubm ed/18971485.

Daskalopoulou SS, Mikhailidis DP, \& Elisaf M 2004. Prevention and treatment of the metabolic syndrome. Angiology, 55(6), 589-612.

Grundy SM, Hansen B, Smith SC Jr, et al., 2004 Clinical management of metabolic syndrome: report of the American Heart Association/National Heart, Lung, and Blood Institute/American Diabetes Association conference on scientific issues related to management. Circulation. 2004; Pubmed; 109:551-556. Diakses pada 18 September 2017 dari https://www.ncbi.nlm.nih.gov/pubm ed/14757684.

Kaur J 2014. A Comprehensive Review on Metabolic Syndrome. Hindawi Publishing Corporation Cardiology Research and Practice. Volume 2014.

Kleinbaum DG, Kupper LL and Morgenstern H 1982. Epidemiologic Research: Principles and Quantitative Methods. New York: Van Nostrand Reinhold.

Rini S 2015. Sindrom metabolik. J Majority, $4(4), 88-93$. 